\title{
MACHADO DE ASSIS DRAMATURGO: \\ ESBOÇO PARA UMA GRANDE PINTURA
}

\section{MACHADO DE ASSIS PLAYWRITER: A SKETCH FOR A GREAT PAINTING}

\author{
André Luís Gomes*
}

RESUMO: Machado de Assis dedicou-se intensamente ao teatro durante a década de 1860-70, seja como dramaturgo ou crítico teatral. Essa dedicação responde ao contexto social e político de sua época e pode ser entendido como um exercício para o desenvolvimento do grande contista e romancista Machado de Assis. Nosso objetivo é acentuar a necessidade de se estudar a obra teatral de Machado de Assis e identificar elementos temáticos e estruturais esboçados em suas peças que vão se desenvolver em seus contos e romances.

PALAVRAS-CHAVE: Literatura Brasileira, Machado de Assis, teatro, crítica teatral.

\begin{abstract}
Machado de Assis was dedicated intensely to the theater during the decade of 1860-70as as a playwriter or theatrical critic. This dedication responds to the social and political context of his time and can be understood like an exercise for the development of the great story writer and novelist Machado de Assis. Our objective is to accent the necessity of being studied the theatrical work of Machado de Assis and to identify thematic and structural elements sketched in his pieces what they are going to develop in his stories and novels.

KEY WORDS: Brazilian literature, Machado de Assis, theatrical criticism
\end{abstract}

* Prof. Dr. do Departamento de Teoria Literária e Literaturas da Universidade de Brasília (UnB). 



\section{MACHADO DE ASSIS DRAMATURGO: \\ ESBOÇO PARA UMA GRANDE PINTURA.}

O título deste artigo nos remete diretamente às considerações de Quintino Bocaiúva a respeito de duas peças de Machado de Assis, O Caminho da Porta e O Protocolo, representadas em 1862 e publicadas no ano seguinte. Em resposta ao amigo, Quintino Bocaiúva não deixa de expressar sua opinião sincera: considera as duas comédias "uma ginástica de estilo" e propõe que o jovem dramaturgo aprimore a sua técnica teatral para transformar em grande pintura o que até então eram "esboços".

A opinião de Quintino Bocaiúva pode ser entendida como uma possível explicação para o desinteresse de estudiosos pelo dramaturgo Machado de Assis quando comparado ao interesse pelo romancista e contista. Desinteresse que não se justifica quando se verifica que o teatro sempre esteve presente na vida literária machadiana, principalmente, no início de sua carreira, como afirma João Roberto Faria:

O envolvimento de Machado de Assis com o teatro, principalmente no início de sua carreira literária, foi bastante expressivo. Entre 1859, quando tinha vinte anos de idade, e 1867, ele foi crítico teatral, dramaturgo, censor do Conservatório Dramático e tradutor de várias peças francesas. (FARIA, 2003, p. IX) 
Em recente entrevista ${ }^{1}$, Jean-Michel Massa sugere uma nova fase na história literária de Machado de Assis, tendo em vista justamente a presença do Teatro na vida do autor, e "esta fase, entre os anos 1860 e 1870, isto é, praticamente antes do casamento, poderia chamar-se fase teatral. Isso porque, àquela altura, Machado não só fez inúmeras traduções de teatro, umas quinze já conhecidas, mas também teve no teatro a base de sua vida literária”. Esta sugestão vai ao encontro do desejo de alguns estudiosos da obra machadiana que, desde a década de sessenta do século passado, já apontavam o pouco destaque que o teatro de Machado de Assis mereceu da crítica especializada. Há, de fato, poucos estudos sobre a dramaturgia, a crítica e as traduções teatrais de nosso iniciador do Realismo brasileiro. Esta constatação já era sentida e apontada por Joel Pontes, que, em 1960, intitula o primeiro capítulo de seu livro, Machado de Assis e o Teatro, de "Um Machado esquecido":

O certo é que o estudo de Machado de Assis como teatrólogo é inglório. Desmonta uma obra sem brilho, muito longe daquelas perfeições que a crítica já adjetivou, consagradoramente, como machadianas. Não obstante, é um trabalho necessário. No meu caso, é a primeira parte de um estudo futuro, ou, se não for bastante lesto, um serviço a quem empreenda a crítica da obra de Machado, atento não só ao que há de melhor nela mas também ao que há de imaturo e menos original. O simples fato de as peças existirem já obriga o crítico a deterse nelas e mais ainda se lembrarmos que, em certa época, Machado considerou o teatro seu destino literário. (1960, p. 11).

O teatro de Machado de Assis não pode e nem deve ficar no esquecimento, apesar de ter sido considerado inglório, sem brilho ou, como afirmam alguns, apenas para ser lido e não encenado. Não se deve, de fato, buscar, nas peças escritas por ele, o escritor dos grandes romances e contos realistas, mas lê-las, estudá-las e até encená-las a fim de resgatar um gênero que sempre esteve presente na vida pessoal e literária de Machado, o que é também uma forma de entender sua obra como um todo.

John Gledson nos chama a atenção, na introdução de seu livro mais recente Por um novo Machado de Assis, para a necessidade de "enxergar a obra na sua totalidade" e acrescenta:

${ }^{1}$ Cf. A entrevista de Jean-Michel Massa está publicada na Teresa: revista de literatura brasileira n. 6/7. São Paulo: Editora 34/ Imprensa Oficial, 2006, p. 457-466. 
Tenho a impressão de que Machado lançava mão de determinados gêneros em momentos diferentes e que seus impulsos criativos achavam sua melhor expressão não somente nos romances, mas nos contos e até mesmo, às vezes, nas crônicas. (...) Mas ainda estamos muito longe de poder escrever algo semelhante sobre as crônicas. Onde a poesia se insere? E o teatro? Sem alguma idéia da longue durée, por assim dizer, das questões e objetivos da sua obra ao longo prazo, mal podemos avançar; e, claro, o trabalho de Schwarz, e, de uma maneira mais modesta, o meu e de outros não podem ser ignorados. (GLEDSON, 2006, p. 26).

Roberto Schwarz, em "Duas notas sobre Machado de Assis", afirma insistir na análise dos primeiros romances, a fim de demonstrar que a "análise social que desenvolvem, sendo inteligente e vigorosa, não visava a transformação da ordem, mas o seu aperfeiçoamento, além de ser um modo de se fazer aceitar e admirar" (1987, p. 176). O intenso envolvimento de Machado com o Teatro se ajusta à afirmação de Schwarz, afinal, suas peças, sem nenhuma intenção de subverter a ordem, encontramos personagens femininas fortes e inteligentes e, como veremos adiante, geralmente, capazes de inverter o jogo e passarem de conduzidas para condutoras da ação dramática. E o teatro é a forma que nosso autor adota para se inserir socialmente, pois, como nos lembra Schwarz nesse mesmo ensaio:

(Machado) Praticava a poesia, a crítica literária e teatral, publicava crônicas e contos, adaptava teatro do francês, escrevia peças próprias, recitava versos comemorativos, fazia parte do Conservatório Dramático, da Arcádia Fluminense, participava de campeonatos de xadrez, da diretoria do Club Beethoven, era freqüentador do teatro lírico, para o qual compôs libretos, foi candidato - sem querer - a deputado, traduzia e escrevia romances. (p. 176).

Apesar dessa participação na vida cultural nascente do Rio de janeiro, os poucos trabalhos sobre as peças teatrais e a crítica teatral escritas por Machado, geralmente, lamentam o descaso que os estudiosos têm para com essa fase adjetivada de teatral por Jean Michel Massa. Mas, ao mesmo tempo, esses trabalhos trazem esclarecimentos sobre o dramaturgo e crítico Machado de Assis e apontam possibilidades de análises e comparações que não podem ser, seguindo o pensamento de Gledson, da mesma forma ignorados. As dúvidas e as inquietações do conceituado crítico inglês pai- 
ram também sobre o teatro machadiano, afinal, por que Machado lançou mão desse gênero em determinado período? Acompanhava apenas o modismo da época em que grandes escritores escreveram para o palco? $\mathrm{Ou}$ encontrou nesse gênero um modo operante de divulgar sua habilidade de escritor e suas idéias e seu projeto nacionalista? Até que ponto esse "exercício teatral" transformou o escritor de esboços teatrais no "grande pintor" de romances e contos realistas? A crítica teatral revela o pensamento do escritor sobre o Teatro Brasileiro? Estaria ali também um esboço de um "teórico do teatro" no Brasil? Ou de um mestre que ensina através de uma crítica valorativa o que faz de um ator um grande intérprete? Algumas respostas estão em O teatro realista no Brasil 1855-1865 e na apresentação do Teatro de Machado de Assis, trabalhos escritos por João Roberto Faria e no breve levantamento feito por Joel Pontes ${ }^{2}$ de peças e dramaturgos citados em alguns romances de Machado.

O que se observa é que a experiência teatral de Machado, seja como dramaturgo ou crítico, pode ser observada nos romances e contos em que o autor, em alguns trechos, opta por mostrar a cena através de diálogos ao invés de apresentá-las através de um narrador; no interesse das personagens pelos espetáculos teatrais e nas referências a peças e dramaturgos.

Entre as citações e referências, Otelo, de Shakespeare é, certamente, a mais conhecida e motivou, em 1960, Helen Cadwell a escrever The Brazilian Othello of Machado de Assis ${ }^{3}$ em que a autora argumenta, pela primeira vez, que Capitu é inocente e aproxima o romance machadiano da tragédia Otelo, de Shakespeare. A diretriz comparativista é explicitada pelo próprio personagem-narrador, que dedica três capítulos do romance à tragédia shakesperiana, "Uma ponta de Iago", "Uma reforma dramática" e "Otelo" e a autora se atém a esse caminho intertextual e elogia a habilidade de Machado em estabelecer um fecundo diálogo com o tragediógrafo:

“(...) devemos invejar o Brasil por esse escritor que, com tanta constância, utilizou nosso Shakespeare como modelo - personagens, tramas e idéias de Shakespeare tão habilmente fundidos em seus enredos próprios (...)" (CADWELL, 2002, p. 11).

${ }^{2}$ Cf.: Joel Pontes, em Machado de Assis e o Teatro, faz um breve levantamento das peças e dramaturgos citados nos romances Dom Casmurro, Memórias Póstumas de Brás Cubas, Quincas Borba. (p. 14-15).

${ }^{3}$ Cf.: Em 2002, a editoria Ateliê publicou a tradução de The Brazilian Othello of Machado de Assis, realizada pelo tradutor Fábio Fonseca de Melo. Vide bibliografia. 
John Gledson cita outro exemplo: o conto "Verba testamentária", que se "concentra exclusivamente em eventos culturais, sobretudo o teatro", e essa concentração não surpreende o crítico:

Não há nada de surpreendente nisso para quem saiba alguma coisa sobre a juventude de Machado nos anos 1850 e 60, quando ele, com José de Alencar e outros, participou ativamente do movimento geral para a criação de um teatro nacional que, como todos bem sabiam, dependia, por sua vez, de um público nacional (embora eles reivindicassem a fundação de um equivalente da Comédie Française, financiado com dinheiro da nação). (GLEDSON, 2006, p. 85)

A crítica teatral de Machado de Assis também revela seu modo de pensar a cena teatral, mas, principalmente, os aspectos sociais de sua época, e essas reflexões estabelecem relações entre o teatro, os acontecimentos culturais e as condições políticas e econômicas de sua época, que são transmutados para seus contos e romances.

Neste ensaio, propomo-nos a apresentar de forma panorâmica as peças teatrais escritas por Machado de Assis, estabelecendo ou incitando comparações com as temáticas desenvolvidas em seus romances e contos.

$\mathrm{O}$ autor dedicou-se ao teatro intensamente entre 1859 e 1867, período em que acumulou, como já apontamos, uma série de atividades teatrais e, como dramaturgo, escreveu: Hoje avental, amanhã luva (1860); Desencantos (1861); O caminho da porta (1862); O protocolo (1862); Quase ministro (1862); As forcas caudinas (1865); e Os deuses de casaca (1865). Dentre essas peças, Machado assistiu à encenação de O Caminho da porta e O protocolo, no Ateneu Dramático; e de Quase ministro e Os deuses de Casaca, respectivamente, na intimidade dos saraus da Rua da Quitanda e da Arcádia Fluminense. Depois de um grande período dedicado aos romances e contos, Machado escreve Tu, só tu, puro amor (1880), Não consultes médico (1896), e Lição de botânica (1906).

Com apenas 20 anos de idade, lança-se como comediógrafo com Hoje avental, amanhã luva, em A Marmota. Trata-se, na verdade, de uma imitação da comédia francesa Chasse au lion, de Gustave Nadeu e Émile de Najac. A prática de "imitar" era comum na época e consistia em adequar o enredo original ao contexto social. Nosso comediógrafo inicia essa adequação situando a obra no carnaval de 1859, no Rio de Janeiro. Três personagens dividem a cena, Durval, Rosinha e Bento, apesar da Sra. Sofia de Melo, 
que nunca aparece, ser responsável pelo desenrolar da trama. Durval, galã quarentão e conquistador, volta da roça para reencontrar Sofia, mas não deixa de galantear a criada Rosinha. A criada, que já cedeu aos galanteios do quarentão no passado, recusa-se a beijá-lo.

Um jogo de sedução se estabelece e o cômico nasce da inversão de papéis: ele julga, a princípio, ser fácil enganar a criada e se comporta como um conquistador barato com certo ar de superioridade, mas Rosinha o supera no engodo, conquistando-o. A criada sabe que ele quer ir ao baile acompanhado, por isso arma um plano não só para ir ao baile, mas também para convencê-lo a desposá-la. Bento, o boleeiro, escreve um cartão subscrito a ela e lhe traz um bouquet como se fosse de um admirador espanhol. Mais tarde, Bento disfarça sua voz com sotaque espanhol e convida a criada para ir ao baile. Durval, enciumado, declara seu amor. Rosinha o acompanha ao baile e consegue, finalmente, um noivo.

A criada é sedutora, dissimulada e perspicaz e conduz o jogo que a faz sentir-se, ao final, "vingada". Sofia não entra em cena, mas se faz presente o tempo todo por meio das falas de Durval e Rosinha. Nessa comédia curta de um único ato, com onze cenas, ambas são fortes, perspicazes e decididas, características que vão aparecer nas personagens dos romances e contos machadianos.

A leveza do texto deve-se à despretensão do dramaturgo em aprofundar questões sociais e discutir, por exemplo, a condição de uma empregada no século XIX, tratada de forma preconceituosa por um quarentão sedutor. O jogo cômico emerge da inversão dos papéis do enganado e do enganador e, neste jogo, quem assume o papel de inteligente e perspicaz é a personagem feminina, enquanto o de tolo fica, justamente, para Durval.

Depois de sua estréia com a "imitação" de uma comédia, Machado escreve Desencantos, uma fantasia dramática, dividida em duas partes e com três personagens, Clara de Souza, uma viúva, e dois jovens vizinhos, Luís de Melo e Pedro Alves. A ação se passa em um jardim em Petrópolis e, na segunda parte, em uma sala de estar. Na primeira parte, os dois jovens disputam o amor de Clara. Pedro Alves é racional e a conquista, e Luís, poeta e sonhador, segue para o Oriente. Na primeira cena da segunda parte, Pedro Alves, deputado ministerialista, condena o comportamento da esposa Clara, que quer ir a uma partida do membro da oposição e os conflitos do casal se evidenciam. Na cena III, Luís adentra a cena e o espectador fica sabendo que ele esteve alguns anos no orienta. Na cena VI, Luís confessa 
estar apaixonado justamente pela filha de Clara, que tem o mesmo nome da mãe. Os pais de Clarinha concordam com o casamento e, na cena final, pedem que Luís a faça feliz.

Machado publica as comédias $O$ caminho da porta e $O$ protocolo após o sucesso de estréia. Apesar da boa recepção do público, Quintino Bocaiúva, em carta já mencionada no início deste texto, as considera "frias e insensíveis" e peças "para serem lidas e não representadas".

$\mathrm{Na}$ primeira comédia, Carlota tem dois pretendentes, Valentim e Inocêncio, que perseguem o caminho do coração da viúva. Enquanto o Doutor Cornélio, desconfiado do interesse de ambos pela viúva, aconselhaa em longas falas discursivas, acumulando provérbios e defesas a este ou àquele comportamento, o jovem poeta vai e volta à cena buscando caminhos que o levem ao coração da viúva, assim como faz o velho Inocêncio. Ambos se convencem, no final, de que "quando não se pode atinar com o caminho do coração, deve-se tomar sem demora o caminho da porta”.

Com diálogos mais caseiros, aparecem, em O protocolo, novo triângulo amoroso e o tema do adultério. Pinheiro e Elisa passam por uma crise no casamento e Venâncio se aproxima do casal com a intenção de conquistála. Lulu, jovem que mora com o casal, adverte Pinheiro das verdadeiras intenções de Venâncio. O marido, enciumado, mas convencido da fidelidade da esposa, coloca Venâncio para fora de casa e, na cena final, o casal celebra a paz restabelecida.

Quase ministro difere das outras peças que giram em torno de conquistas amorosas. Escrita para ser representada em um sarau literário, a comédia se constrói a partir de um boato: o deputado Luciano Martins foi convidado a ocupar a pasta de ministro. O boato se espalha pela cidade e interesseiros, bajuladores chegam à casa de Martins, que desconhece tal convite. A peça, escrita por encomenda para um sarau, só tem personagens masculinas: Luciano Martins, o deputado; doutor Silveira, seu primo; José Pacheco, jornalista bajulador em busca de verba para publicar um folheto que lhe trará fama; Carlos Bastos, escritor que pretende patrocínio para a publicação de seus poemas; Mateus, inventor de uma peça de artilharia que está em busca de apoio para sua invencionice que colocará, segundo ele, na mão do país a soberania do mundo; Luís Pereira, um puxa saco que oferece jantares aos ministros e os convida para padrinho de seus filhos; e Müller, que chegou da Europa e deseja contratar o Teatro Lírico. O deputado atende a quase todos, mas se retira e deixa que o primo atenda Luis Pereira e 
Müller. Quando retorna, todos estão em sua casa e ele então esclarece que tudo não passou de boato, pois o ministério está completo. Os bajulares e interesseiros vão se retirando cada um com uma desculpa desajeitada, o que provoca risos no leitor e, certamente, no espectador. Considerada entre as melhores do teatro machadiano, essa comédia revela o talento de um comediógrafo que escreve por encomenda, tarefa que alguns escritores se recusam a atender.

Escrita entre 1863 e 1865, As forcas caudinas pode ser considerada um provérbio dramático, como a define João Roberto Faria 4 . São dois atos em que Emília, viúva de apenas 25 anos, propõe-se a conquistar Tito, jovem que, devido a uma desilusão amorosa, promete a si mesmo não mais amar ninguém. A princípio, a viúva conduz o jogo amoroso, mas acaba por ele conduzida, pois se apaixona por Tito, que a despreza. Depois de um certo sofrimento, descobre-se que a mulher que o havia desprezado era Emília. Tito, então, resolve confessar que havia procedido daquela forma de modo a se fazer desejado e conquistá-la.

De 1865, Os deuses de casaca só tem personagens masculinos: Júpiter, Marte, Apolo, Proteu, Cupido, Vulcano e Mercúrio; exigência da Arcádia Fluminense, onde a comédia foi encenada. Os deuses resolvem conviver com os humanos e cedem às imperfeições mundanas.

Depois desse período de intensa dedicação ao teatro, Machado passa a se dedicar esporadicamente à escrita de textos teatrais. Aceita novamente a tarefa de escrever uma peça com um objetivo específico: participar das comemorações do tricentenário da morte de Camões. Tu, só tu, puro amor, representada em 1880, é uma homenagem singela ao jovem Camões e considerada uma "jóia literária”, em que Machado concilia sua linguagem habitual à arcaica.

Depois de 16 anos, volta ao gênero de comédia com Não consultes médico. No entanto, a maturidade do autor de Memórias Póstumas de Brás Cubas e Dom Casmurro não migra para essa comédia, que ganha apenas em leveza e comicidade. Como é característico do teatro machadiano, temos poucas personagens: D. Leocádia, D. Carlota, D. Adelaide, Cavalcante e Magalhães. Devido às desavenças amorosas, Cavalcanti e Carlota quase

\footnotetext{
${ }^{4}$ Cf. Em "A comédia refinada de Machado de Assis", texto de apresentação do livro O Teatro de Machado de Assis, João Roberto Faria comenta cada uma das comédias machadianas, aproximando algumas ao provérbio dramático.
} 
se afastam, mas, ambos consultam, ao invés de médico, D. Leocádia e, no final, vencida a timidez, entendem-se e se casam.

Na última comédia, Lição de Botânica, escrita em 1905 e publicada no ano seguinte, Machado de Assis aproveita um argumento já desenvolvido em comédias anteriores, mas agora demonstrando domínio de certa carpintaria teatral. São três mulheres, D. Helena, D. Leonor e D. Cecília, e o estudioso de botânica, Barão Sigismundo de Kernoberg, que dividem as cenas, cenas estas que têm o amor como centro da intriga. A jovem Cecília está apaixonada por Henrique, sobrinho do Barão. O botânico as surpreende, pois, ao invés de pedir que $\mathrm{D}$. Leonor autorize o namoro, pede que ela feche a porta ao sobrinho, que deve se dedicar ao estudo da botânica, argumentando que "a ciência precisa de mais um obreiro". D. Helena, viúva, resolve ajudar a irmãzinha e tem um plano: resolve conquistar o Barão, demonstrando interesse pela ciência, especificamente, pela botânica. Quando o Barão volta para buscar um livro que havia esquecido, D. Helena coloca seu plano em ação: demonstra interesse por gramíneas, por periantos e se diz interessada em estudar botânica. O Barão se oferece como professor e D. Helena acaba por convencê-lo de que "houve e há sábios casados" e que "a esposa fortifica a alma do sábio". Convencido, o botânico não só aprova o romance de Henrique e Cecília como também pede a mão de D. Helena.

Concluindo, pode-se afirmar que, apesar de ser tão pouco estudado, o teatro de Machado de Assis acumula uma quantidade considerável de adjetivos empregados por parte dos seus estudiosos: escrupuloso; moral e civilizador; adaptado ao gosto do público; pseudo-moral; fino; requintado; de salão; excessivamente alusivo; pedante; burguês etc. Não obstante os qualificativos nem sempre elogiosos, o teatro de Machado merece não só ser lido como representado, tendo em vista o público e as condições de sua época e, ao mesmo tempo, o quanto suas personagens representam tipos que ainda hoje freqüentam os salões e a política nacional.

Não existe nada muito original em destacar o interesse de Machado pela sociedade, história e política brasileiras: é coisa do passado remoto (ou deveria sê-lo) criticá-lo por não refletir a realidade local. Mas, aos poucos, ao longo dos anos, um ponto de vista contraditório foi surgindo, o de que a própria sutileza e a profundidade com que ele espelha as condições locais, brasileiras, são essenciais para sua grandeza e originalidade como escritor. (GLEDSON, 2003, p. 31) 
Essa grandeza está, de certa forma, apenas esboçada no teatro de Machado de Assis, embora plenamente concretizada em seus romances e contos, mas não se pode negar a necessidade do esboço para a grande arte.

\section{Referência Bibliográfica}

1. De Machado de Assis

ASSIS, Machado de. "O ideal crítico". In: .Obras completas. Rio de Janeiro: Ed. José Aguilar, 1962, v.3, p. 798-801.

ASSIS, Machado de. Memórias póstumas de Braz Cubas. Rio de Janeiro: Ed. José Aguilar, 1962. In: Obras completas. Rio de Janeiro: Ed. José Aguilar, 1962b, v.1, p. 508-637.

ASSIS, Machado de. "O passado, o presente e o futuro da literatura". In: . Obras completas. Rio de Janeiro: Ed. José Aguilar, 1962c, v.3, p. 785-789.

ASSIS, Machado de. Relíquias da casa velha. In: . Obras completas.

Rio de Janeiro: Ed. José Aguilar, 1962d, v.1, p. 557-733.

ASSIS, Machado de. Dom Casmurro. São Paulo: Ed. Abril, 1971.

2. Sobre Machado

ATAIIDE, Tristão de. "Machado de Assis, o crítico". In: ASSIS, Machado de. Obras completas. Rio de Janeiro: Ed. José Aguilar, 1962, v.3, p. 779-784.

CADWELL, O Otelo Brasileiro de Machado de Assis. Trad. Fábio Fonseca de Melo. São Paulo: Ateliê Editorial, 2002.

FARIA, João Roberto. O teatro realista no Brasil 1855-1865. São Paulo: Edusp/Perspectiva, 1993.

FARIA, João Roberto. “Apresentação”. In: ASSIS, Machado. Teatro de Machado de Assis. São Paulo: Martins Fontes, 2003.

GLEDSON, John. Por um novo Machado de Assis. São Paulo: Companhia das Letras, 2006.

GLEDSON, John. Machado de Assis: Ficção e História. 2a ed. São Paulo: Paz e Terra, 2003. 
GOMES, E. "O testamento estético de Machado de Assis". In: ASSIS, Machado de. Obras completas. Rio de Janeiro: Aguilar, 1962, v.3, p. 1096-1120.

MASSA, Jean-Michel. "Entrevista” Revista Teresa - Revista do Departamento de Teoria Literária da FFLCH-USP, 2005.

SCHWARZ, Roberto. Machado de Assis: um mestre na periferia do capitalismo. São Paulo: Ática, 1992.

SCHWARZ, Roberto. "Duas notas sobre Machado de Assis”. In: Que horas são?: ensaios. São Paulo: Companhia das Letras, 1987. 